\title{
Visual impairment and multimorbidity in a representative sample of the Spanish population
}

Noe Garin ${ }^{1,2,3}$, Beatriz Olaya ${ }^{1,2,3}$, Elvira Lara ${ }^{1,3}$, Maria Victoria Moneta' ${ }^{1}$, Marta Miret ${ }^{3,4}$, Jose Luis Ayuso-Mateos ${ }^{3,4,5}$ and Josep Maria Haro ${ }^{1,2,3^{*}}$

\begin{abstract}
Background: In the context of population aging, visual impairment has emerged as a growing concern in public health. However, there is a need for further research into the relationship between visual impairment and chronic medical conditions in the elderly. The aim of our study was to examine the relationship between visual impairment and three main types of co-morbidity: chronic physical conditions (both at an independent and additive level), mental health and cognitive functioning.

Methods: Data were collected from the COURAGE in Europe project, a cross-sectional study. A total of 4,583 participants from Spain were included. Diagnosis of chronic medical conditions included self-reported medical diagnosis and symptomatic algorithms. Depression and anxiety were assessed using CIDI algorithms. Visual assessment included objective distance/near visual acuity and subjective visual performance. Descriptive analyses included the whole sample $(n=4,583)$. Statistical analyses included participants aged over 50 years $(n=3,625$; mean age $=66.45$ years) since they have a significant prevalence of chronic conditions and visual impairment. Crude and adjusted binary logistic regressions were performed to identify independent associations between visual impairment and chronic medical conditions, physical multimorbidity and mental conditions. Covariates included age, gender, marital status, education level, employment status and urbanicity.

Results: The number of chronic physical conditions was found to be associated with poorer results in both distance and near visual acuity [OR 1.75 (Cl 1.38-2.23); OR 1.69 (Cl 1.27-2.24)]. At an independent level, arthritis, stroke and diabetes were associated with poorer distance visual acuity results after adjusting for covariates [OR 1.79 (Cl 1.46-2.21); OR 1.59 (Cl 1.05-2.42); OR 1.27 (1.01-1.60)]. Only stroke was associated with near visual impairment [OR 3.01 (Cl 1.86-4.87)]. With regard to mental health, poor subjective visual acuity was associated with depression [OR 1.61 (Cl 1.14-2.27); OR 1.48 (Cl 1.03-2.13)]. Both objective and subjective poor distance and near visual acuity were associated with worse cognitive functioning.
\end{abstract}

Conclusions: Arthritis, stroke and the co-occurrence of various chronic physical diseases are associated with higher prevalence of visual impairment. Visual impairment is associated with higher prevalence of depression and poorer cognitive function results. There is a need to implement patient-centered care involving special visual assessment in these cases.

Keywords: Epidemiology, Chronic conditions, Multimorbidity, Visual impairment, Low vision, Mental health, Cognitive functioning, Elderly

\footnotetext{
* Correspondence: jmharo@pssjd.org

${ }^{1}$ Parc Sanitari Sant Joan de Déu, Universitat de Barcelona, Dr Antoni Pujades,

42, 08830 Barcelona, Sant Boi de Llobregat, Spain

${ }^{2}$ Fundació Sant Joan de Déu, Santa Rosa, 39-57, 08950 Barcelona, Esplugues

de Llobregat, Spain

Full list of author information is available at the end of the article
} 


\section{Background}

Visual impairment is related to higher morbidity, increased risk of falling, activity limitations, lower quality of life, poor social participation and increased mortality [1-8]. Low vision is a state of moderate or severe visual impairment defined as a visual acuity lower than 6/18 and equal to or better than $3 / 60$ in the better eye with best correction [9]. Even though this represents significant impairment, people affected with low vision are still potentially able to perform some activities for which sight is essential. The relevance of vision to health status has led the World Health Organization to recently introduce vision and other sensory functions as health domains in the International Classification of Functioning, Disability and Health (ICF), a unified framework for a description of health that highlights the interaction between health conditions and contextual factors [10].

In industrialized countries, the main causes of low vision and blindness are age-related macular degeneration (AMD), glaucoma, cataracts, pathologic myopia and diabetic retinopathy. The prevalence of all these disorders increases with age $[11,12]$. In fact, about $65 \%$ of people who are visually impaired are aged 50 and older, while this group only represents about $20 \%$ of the world's population [13]. Since a 2-fold increase in the population over 60 years old is expected between 2006 and 2050, the number of people with impaired vision is expected to increase in the future [14,15]. Although some of these disorders can be treated, for instance through cataract surgery or AMD intravitreal pharmacotherapy, permanent functional visual impairment can appear in cases of delayed or inefficacious treatment [16].

Aging is also clearly associated with the onset of chronic physical and mental conditions and an increase in multimorbidity $[17,18]$. According to a recent review, between $55 \%$ and $98 \%$ of the elderly population suffer from multimorbidity [19]. Some particular associations have been identified between chronic physical conditions and vision disorders, such as diabetes and retinopathy [20]. However, there is very limited information on the relationship between visual functioning and most common medical chronic conditions at both the independent and additive levels. Sensory impairment has also been linked to psychological and social problems. Mild or moderate visual impairment in adults have been found to be associated with mental distress, depression, anxiety, suicide risk, interpersonal sensitivity and hostility [2,21-26]. Most of these studies have focused on depression and little is known about the relationship between sensorial impairment and other psychiatric conditions, such as anxiety, especially in the elderly. Moreover, there is evidence of an association between visual impairment and dementia $[27,28]$. To date, however, research focusing specifically on the association between visual impairment and cognitive functioning has showed mixed results [29-33]. Determining the relationship between visual impairment and chronic conditions through a comprehensive approach might contribute to the development of optimal patient-centered care to the elderly.

We used a large general population survey to examine:

- The relationship between physical multimorbidity and visual impairment in the population over 50 years old.

- The relationship between visual impairment and mental health (depression and anxiety) in the population over 50 years old.

- The relationship between visual impairment and cognitive functioning in the population over 50 years old.

\section{Methods}

\section{Design}

The COURAGE in Europe project is a cross-sectional household survey of a representative sample of the noninstitutionalized adult population conducted in Finland, Poland and Spain [34]. Data from the Spanish sample are analyzed in the current study.

\section{Sample and procedures}

A representative sample of the adult population in Spain was selected using a stratified multistage clustered area probability method. The target group was a communityresiding population over 18 years. Three samples were selected according to age: $18-49 ; 50-79 ; \geq 80$ years. The $50+$ and $80+$ subgroups were oversampled as they were the main target of the study. People with language barriers were excluded. From July 2011 to May 2012, face-to-face structured interviews were conducted through ComputerAssisted Personal Interviewing (CAPI) at respondents' homes. The survey protocol was translated from English into Spanish according to WHO translation guidelines for assessment instruments [35]. Lay interviewers were trained before administration of the survey. Quality assurance procedures were implemented during fieldwork [36]. The final response rate was $69.9 \%$. The main reason for non-response was that the house was unoccupied or that the members of the household were elsewhere (seasonal vacancy, other residence). The interviewer judged whether the respondent had cognitive problems at the beginning of the interview. If cognitive difficulties were evident, a short version of the survey was obtained from proxy respondents. Data from proxy respondents were not analyzed since visual assessment and diagnosis of chronic physical conditions and mental disorders were not performed in the proxy interviews. Therefore, once the 170 proxy respondents had been eliminated, the final analysis consisted of 4,583 participants. This sample was used 
for initial descriptive purposes. The final analysis consisted of 3,625 participants over 50 years old since this subgroup suffers from significant prevalence of chronic conditions and visual impairment compared with younger populations.

\section{Data collection}

Sociodemographic information included age, gender, marital status, education level, employment status and urbanicity. With regard to chronic physical conditions, participants were asked whether they had received lifetime medical diagnosis and treatment during the previous 12 months for angina, arthritis, asthma, chronic lung disease, diabetes, edentulism, hypertension and stroke. Moreover, algorithms based on clinical symptoms were implemented to detect undiagnosed cases. These were based on the WHO's SAGE study, current clinical guidelines and reference publications [37-43]. In the case of meeting at least one of the two previously established criteria, the respondent was considered to have angina, asthma, arthritis, chronic lung disease or stroke. Hypertension, diabetes and edentulism are asymptomatic conditions so no symptomatic algorithm was used. Previous 12-month major depressive disorder and anxiety disorders (including Generalized Anxiety Disorder and Panic Disorder) were assessed with an adapted version of the World Health Organization Composite International Diagnostic Interview (CIDI), according to DSM-IV criteria [44]. Cognitive functioning results were calculated from five performance tests in distinct domains: learning and short-term memory (word list immediate and delayed recall from the Consortium to Establish a Registry for Alzheimer's Disease), attention and working memory (digit spans forward and backward from the Weschler Adult Intelligence Scale) and language (animal naming task) [45,46]. All performance tests were scored according to standard practice for each test. A global score was calculated using the sum of the standardized score on each item, with a lower score indicating worse cognitive functioning [47]. Analogous methodology for computing this score with the same tests has previously been used in the WHO's SAGE and COURAGE studies $[47,48]$. In our case, we also standardized results by level of education. Results were later transformed into a binary variable for analysis purposes. Objective visual acuity was measured by the interviewer with a "tumbling E" chart [49]. To assess distance vision, an appropriate chart was placed 3 meters from the participant. Visual acuity was registered using the metric visual acuity scale, through which patients were classified into one of the following groups: visual acuity less than $3 / 60,3 / 60-6 / 60,6 / 60-6 / 18$ and more than $6 / 18$. To demonstrate the visual acuity required by a line in the chart, the participant had to detect at least three of the four letters in the line. Distance VA was measured initially for the left eye and subsequently for the right eye. Analog procedures were conducted to assess near vision, with a specific appropriate chart that was held by the participant at a comfortable distance. For near vision, participants were classified as: unable to see the largest sized letter $(<\mathrm{N} 48)$, able to see largest size (N48), able to see medium size (N20), able to see the smallest size (N8). All the measures were taken in daily-life light conditions with the participant's usual visual correction. The interviewer made sure that the vision chart was well lit with natural or indoor lighting and that the surface did not reflect glare. Visual performance for distance and near vision was taken from the eye with the better visual acuity results. Subjective visual acuity was assessed through two questions: a) In the last 30 days, how much difficulty did you have in seeing and recognizing an object or a person you know across the road (from a distance of about 20 meters)?; b) In the last 30 days, how much difficulty did you have in seeing and recognizing an object at arm's length (for example, reading)? Five answers were permitted: none, mild, moderate, severe, extreme.

\section{Statistical analysis}

Unweighted frequencies, weighted proportions, means, confidence intervals and cross tabulations were applied for descriptive analyses. The Chi-square test was used to measure differences in visual performance, prevalence of chronic diseases, multimorbidity, number of conditions and sociodemographic variables across age and gender.

Crude and adjusted binary logistic regressions were used to examine the association between chronic physical conditions and visual performance in participants over 50 years $(\mathrm{n}=3625)$. Results are reported as Odds Ratio (OR) with 95\% CI. Adjusted models included age, gender, education level, marital status, urbanicity, and all chronic physical conditions. For the analyses regarding the relationship between multimorbidity and visual performance, adjusted models included age, gender, education level, marital status, urbanicity, and number of chronic conditions. Analogous procedures were used to examine the association between visual acuity and the variables related to mental health (depression, anxiety) and cognitive functioning. In this case, adjusted models included age, gender, education level, marital status, urbanicity and all chronic physical conditions. Visual acuity variables were transformed into binary variables for the logistic regression. Objective distance visual acuity was classified as "poor" (lower than 6/18) or "good" (equal or better than 6/18). Objective near visual acuity was classified as "good" (able to read the smallest letters) or "poor" (other cases). Subjective visual acuity with no or mild problems was considered "good", and "poor" in the case of more serious problems. The Kappa inter-agreement test 
was performed for objective and subjective visual performance. The association was considered as fair (Kappa: 0.3206; Standard Error: 0.0118) [50]. For this reason, objective and subjective visual performance were taken into account separately in the logistic regression relating vision and mental health.

The statistical analyses took into consideration the complex nature of the sample design. Weights were used in all analyses to adjust for differential probabilities of selection within households, and post-stratification weights to match the samples to population socio-demographic distributions. Analyses were performed using IBM SPSS statistics 19.

\section{Ethics statement}

The COURAGE study was approved by the partners' Ethics Committees: Fundació Sant Joan de Déu Ethics Review Committee, Barcelona, Spain and La Princesa University Hospital Ethics Review Committee, Madrid, Spain. Written informed consent was obtained from the participants. All investigators worked according to the principles expressed in the Declaration of Helsinki.

\section{Results}

Participant characteristics

The study population consisted of 4,583 participants. A summary of the sociodemographic data is available in Table 1. Age differences are statistically significant in educational level, marital status and employment. As expected, prevalence of physical multimorbidity, chronic physical conditions and mental conditions increased with age, except for anxiety (Table 2). Cognitive functioning below median per group was: a) 18-49 years: 48.5\% (CI: 44.9-52.1); b) 50-64 years: 65.2\% (CI: 61.568.7); c) 65+: 83.1\% (CI: 80.9-85.0).

In the overall adult population, a decrease in distance visual acuity was observed across age groups (Table 3 ). No gender differences were observed. For near visual acuity, the worst results were found in the elderly and in women. In the population aged over 65 years, only $33.8 \%$ of the women and $43.0 \%$ of the men achieved highest near visual acuity. Age and gender differences were also present in the subjective perception of distance and near vision problems. Elderly women was the group with the poorest results.

Table 1 Description of the sample of the Spanish Cohort of the COURAGE study

\begin{tabular}{|c|c|c|c|c|c|}
\hline & Total sample $(n=4583)$ & $18-49$ years $(n=958)$ & $50-64$ years $(n=1760)$ & $\geq 65$ years $(n=1865)$ & $p$ \\
\hline Age (mean; SE) & $47.6(0.3)$ & $35.7(0.30)$ & $57.0(0.1)$ & $74.9(0.1)$ & \\
\hline Education (n; \%) & & & & & $<0.001$ \\
\hline No education & 1269 (16.64\%) & $62(6.53 \%)$ & $311(16.62 \%)$ & $896(46.70 \%)$ & \\
\hline Primary & 1265 (24.93\%) & $190(20.92 \%)$ & $548(32.81 \%)$ & $527(29.84 \%)$ & \\
\hline Secondary & 1423 (39.29\%) & 474 (48.07\%) & $638(35.42 \%)$ & $311(16.61 \%)$ & \\
\hline$\geq$ University & $625(19.14 \%)$ & $232(24.48 \%)$ & $263(15.15 \%)$ & $130(6.80 \%)$ & \\
\hline Gender (n; \%) & & & & & 0.006 \\
\hline Male & 2078 (49.4\%) & 435 (51.35\%) & $829(47.70 \%)$ & $814(44.95 \%)$ & \\
\hline Female & $2505(50.6 \%)$ & $523(48.65 \%)$ & $931(52.30)$ & $1051(55.04 \%)$ & \\
\hline Marital status (n; \%) & & & & & $<0.001$ \\
\hline Single & $667(27.3 \%)$ & $357(39.18 \%)$ & 187 (10.39\%) & $123(6.75 \%)$ & \\
\hline Married & $2777(56.6 \%)$ & $519(53.12 \%)$ & $1238(71.10 \%)$ & $1020(54.18 \%)$ & \\
\hline Separated/divorced & $342(7.1 \%)$ & $76(7.21 \%)$ & $196(10.86 \%)$ & $70(3.36 \%)$ & \\
\hline Widowed & 797 (9.0\%) & $6(0.49 \%)$ & $139(7.64 \%)$ & $652(35.72 \%)$ & \\
\hline Urbanicity (n; \%) & & & & & 0.216 \\
\hline Urban & $3958(84.78 \%)$ & $820(85.40 \%)$ & $1523(83.69 \%)$ & 1615 (83.93\%) & \\
\hline Rural & $625(15.22 \%)$ & $138(14.60 \%)$ & $237(16.31 \%)$ & $250(16.07 \%)$ & \\
\hline Employment (n; \%) & & & & & $<0.001$ \\
\hline Working & 1360 (46.21\%) & $543(61.34 \%)$ & 773 (47.47\%) & 44 (2.28\%) & \\
\hline Retired & 1387 (16.43\%) & $2(0.24 \%)$ & 183 (11.35\%) & $1202(66.56 \%)$ & \\
\hline Other & 1611 (37.36\%) & 342 (38.41\%) & $681(41.18 \%)$ & 588 (31.16\%) & \\
\hline
\end{tabular}

$\mathrm{SE}=$ Standard Error.

Note $=$ unweighted frequencies ( $\mathrm{n}$ ), and weighted means and proportions are displayed. Household income was divided into 5 quintiles. Education category 'no education' included those people that had never been to school or did not finish primary school. Marital status 'married' category included currently married or cohabiting. Employment 'other' category included training, homemakers, unemployed, voluntary work, health problems, caring for family, sick leave, no need to work, temporary time off and voluntary work. 
Table 2 Prevalence of 12-month chronic physical conditions, mental disorders and multimorbidity according to age

\begin{tabular}{|c|c|c|c|c|c|}
\hline & Total & $18-49$ years & $50-64$ years & $\geq 65$ years & $p$ (age) \\
\hline Angina & $2.84(2.44-3.29)$ & $0.4(0.2-0.9)$ & $3.8(2.9-4.9)$ & $9.2(7.9-10.7)$ & $<0.001$ \\
\hline Asthma & $4.83(4.11-5.67)$ & $3.9(2.9-5.1)$ & $4.3(3.5-5.4)$ & $8.1(6.7-9.7)$ & $<0.001$ \\
\hline Hypertension & $16.55(15.48-17.68)$ & $3.4(2.3-5.0)$ & $23.4(21.3-25.7)$ & $49.7(47.4-52.0)$ & $<0.001$ \\
\hline Edentulism & $9.03(7.67-10.60)$ & $2.8(1.6-5.0)$ & $8.2(6.8-9.9)$ & $28.3(25.0-31.8)$ & $<0.001$ \\
\hline Diabetes & $6.66(5.95-7.45)$ & $2.0(1.3-3.0)$ & $9.5(7.9-11.3)$ & $18.1(16.2-20.1)$ & $<0.001$ \\
\hline Arthritis & $13.72(12.66-14.84)$ & $5.4(4.2-7.0)$ & $18.4(16.4-20.6)$ & $34.3(31.8-36.9)$ & $<0.001$ \\
\hline Chronic Lung D & $3.35(2.83-3.95)$ & $1.2(0.7-2.1)$ & $4.0(3.1-5.1)$ & $9.1(7.7-10.8)$ & $<0.001$ \\
\hline Stroke & $2.13(1.71-2.64)$ & $0.5(0.3-1.2)$ & $2.4(1.6-3.5)$ & $6.6(5.3-8.3)$ & $<0.001$ \\
\hline Depression & $8.97(7.88-10.19)$ & $7.0(5.5-8.8)$ & $12.0(9.8-14.5)$ & $12.2(10.6-13.9)$ & $<0.001$ \\
\hline Anxiety & $1.09(0.77-1.54)$ & $0.9(0.5-1.7)$ & $1.8(1.3-2.5)$ & $1.0(0.7-1.6)$ & 0.120 \\
\hline \multicolumn{6}{|c|}{ Number of physical conditions } \\
\hline 0 & $64.4(62.7-66.1)$ & $82.8(80.3-85.0)$ & $53.0(49.4-56.5)$ & 19.9 (17.9-22.1) & $<0.001$ \\
\hline 1 & $21.3(19.9-22.7)$ & $15.3(13.2-17.7)$ & $29.7(27.3-32.3)$ & $31.5(29.7-33.4)$ & $<0.001$ \\
\hline 2 & $8.1(7.5-8.8)$ & $1.4(0.9-2.2)$ & $10.3(8.8-12.1)$ & $26.3(24.2-28.5)$ & $<0.001$ \\
\hline$\geq 3$ & $6.2(5.6-6.8)$ & $0.5(0.2-1.2)$ & $7.0(5.8-8.3)$ & $22.3(20.1-24.7)$ & $<0.001$ \\
\hline
\end{tabular}

Note $=$ Weighted proportion and 95\% Confidence Intervals are shown. Anxiety included Generalized Anxiety Disorder and Panic Disorder.

\section{Association between physical health and visual acuity}

Table 4 shows the crude and adjusted logistic regression odds ratios for the association between visual acuity and physical medical conditions in individuals over 50 years old $(\mathrm{n}=3,625)$. In the crude analysis, all chronic physical conditions except chronic lung disease were associated with worse distance visual acuity. In the adjusted model, arthritis, stroke and diabetes were still associated with worse distance visual acuity after adjusting for other covariates (OR 1.79 [CI 1.46-2.21]; OR 1.59 [CI 1.05-2.42]; OR 1.27 [1.01-1.60] respectively). Similar results were found in the analysis of near visual acuity, although only stroke resulted in a higher odds of worse visual acuity (OR 3.01 [CI 1.86-4.87]) after adjusting for covariates. The number of concurrent chronic physical conditions was associated with an increased odds of worse visual acuity for both near and distance vision. In the adjusted model for distance visual acuity, patients with three or more chronic physical conditions had the highest odds (OR 1.75 [CI 1.38-2.23]). Similar results were found with regard to the number of chronic physical conditions and near visual acuity. The highest OR was associated with having three or more chronic diseases (OR 1.69 [CI 1.27-2.24]).

Association between visual acuity and variables related to mental health and cognition

After adjusting for covariates, subjective distance visual acuity and subjective near visual acuity were revealed to be associated with depression (OR 1.61 [CI 1.14-2.27]; OR 1.48 [CI 1.03-2.13]) (Table 5). No association was found in any visual acuity variable with regard to anxiety in the logistic model adjusting for covariates. For cognition, objective distance visual acuity, objective near visual acuity, subjective distance visual acuity and subjective near visual acuity were associated with lower cognitive performance in the adjusted model (OR 1.27 [CI 1.02-1.59]; OR 1.51 [CI: 1.28-1.85]; OR 1.43 [CI 1.00-2.06]; OR 2.40 [CI 1.52-3.71])

\section{Discussion}

Our study found a clear relationship between suffering from various co-occurring chronic physical conditions and poorer distance and near visual performance. Independently, arthritis and stroke were associated with poor visual acuity. With regard to mental health, poor subjective visual acuity was associated with depression. No association was found with anxiety. Both objective and subjective poor VA were associated with worse cognitive performance.

To date, this is the first study that has analyzed the association between suffering from co-occurring physical conditions and the odds of visual impairment, highlighting the additive effect of chronic conditions. After adjusting for covariates, our results show an increasing odds of poor distance and near visual acuity according to the number of chronic physical conditions. Since multimorbidity affects a large proportion of the adult and elderly population, this may be a common risk factor for visual impairment. This is especially important as visual impairment has been related to poorer results in quality of life and disability $[3,6,51]$. The underlying mechanism in this relationship is unknown. By analogy with frailty, in which accumulation of deficits increases vulnerability to adverse 
Table 3 Vision acuity results across age and sex groups

\begin{tabular}{|c|c|c|c|c|c|c|c|c|c|}
\hline & \multirow[t]{2}{*}{ TOTAL } & \multicolumn{2}{|c|}{$18-49$ years } & \multicolumn{2}{|c|}{$50-64$ years } & \multicolumn{2}{|c|}{$>65$ years } & \multirow{2}{*}{$\begin{array}{c}p \\
\text { (age) }\end{array}$} & \multirow{2}{*}{$\underset{\text { (sex) }}{p}$} \\
\hline & & Men & Women & Men & Women & Men & Women & & \\
\hline Objective DVA & & & & & & & & $<0.001$ & 0.113 \\
\hline$\geq 6 / 18$ & 79.7 (76.3-82.8) & $81.6(76.0-86.1)$ & $86.2(82.2-89.4)$ & $83.2(79.8-86.1)$ & $79.7(75.2-83.7)$ & $69.4(64.3-74.0)$ & $62.5(57.7-67.1)$ & & \\
\hline $6 / 60$ & 16.7 (13.9-20.0) & $17.0(12.6-22.4)$ & 11.9 (8.9-15.6) & $15.1(12.3-18.3)$ & $17.7(14.2-21.9)$ & $21.9(18.3-26.1)$ & $25.3(21.6-29.5)$ & & \\
\hline $3 / 60$ & $2.9(2.3-3.8)$ & $1.4(0.5-3.9)$ & $1.6(0.8-3.2)$ & $1.7(1.0-2.9)$ & $2.3(1.5-3.7)$ & $7.0(5.1-9.4)$ & $9.3(7.4-11.7)$ & & \\
\hline$<3 / 60$ & $0.6(0.4-0.9)$ & $0.1(0.0-0.7)$ & $0.3(0.1-1.6)$ & $0.1(0.0-0.4)$ & $0.2(0.1-0.5)$ & $1.7(1.0-3.0)$ & $2.8(1.8-4.5)$ & & \\
\hline Objective NVA & & & & & & & & $<0.001$ & $<0.001$ \\
\hline Smallest letter & $68.8(66.4-71.1)$ & $84.7(81.0-87.99$ & $80.0(76.5-83.1)$ & $59.6(55.8-63.3)$ & $53.7(49.1-58.3)$ & $43.0(38.0-48.1)$ & $33.8(30.1-37.6)$ & & \\
\hline Medium letter & $28.6(26.5-30.9)$ & 14.5 (11.5-18.2) & $18.6(15.6-22.0)$ & $38.1(34.4-41.9)$ & $43.4(39.2-47.8)$ & $50.8(46.0-55.5)$ & $57.9(53.6-62.1)$ & & \\
\hline Large letter & $2.1(1.6-2.7)$ & $0.5(0.2-1.7)$ & $1.4(0.6-2.9)$ & $2.1(1.3-3.3)$ & $2.3(1.4-3.8)$ & $5.1(3.9-6.8)$ & $5.9(4.5-7.7)$ & & \\
\hline $\begin{array}{l}\text { Not large } \\
\text { letter }\end{array}$ & $0.5(0.3-0.8)$ & $0.2(0.0-1.4)$ & 0 & $0.2(0.1-0.8)$ & $0.5(0.2-1.4)$ & $1.1(0.5-2.4)$ & $2.5(1.5-4.1)$ & & \\
\hline $\begin{array}{l}\text { Subjective } \\
\text { DVA }\end{array}$ & & & & & & & & $<0.001$ & $<0.001$ \\
\hline None & $87.8(86.3-89.3)$ & 93.2 (89.7-95.6) & 93.4 (90.9-95.3) & $89.9(87.2-92.0)$ & $83.9(80.4-86.8)$ & 78.5 (74.8-81.8) & $67.5(62.8-71.9)$ & & \\
\hline Mild & $8.3(7.1-9.6)$ & $5.4(3.4-8.5)$ & $5.0(3.4-7.2)$ & $8.2(6.2-10.9)$ & $12.0(9.5-15.1)$ & $14.1(11.6-16.9)$ & $17.0(13.9-20.6)$ & & \\
\hline Moderate & $2.8(2.3-3.5)$ & $0.8(0.2-3.4)$ & $1.4(0.8-2.6)$ & $1.5(0.9-2.5)$ & $3.2(2.2-4.5)$ & $5.7(4.2-7.6)$ & $10.7(8.8-13.1)$ & & \\
\hline Severe & $1.1(0.8-1.4)$ & $0.6(0.2-1.5)$ & $0.2(0.2-0.2)$ & $0.4(0.2-1.1)$ & $1.0(0.5-1.9)$ & $1.8(1.1-2.9)$ & $4.7(3.5-6.3)$ & & \\
\hline $\begin{array}{l}\text { Subjective } \\
\text { NVA }\end{array}$ & & & & & & & & $<0.001$ & 0.506 \\
\hline None & $89.2(87.7-90.6)$ & 93.1 (89.7-95.4) & $96.2(94.5-97.3)$ & $88.3(85.5-90.6)$ & 85.7(82.0-88.8) & $81.4(77.7-84.7)$ & 70.5 (65.6-74.9) & & \\
\hline Mild & $8.0(6.8-9.4)$ & $5.4(3.4-8.6)$ & $3.2(2.1-4.8)$ & $8.6(6.6-11.2)$ & $11.4(8.7-15.0)$ & $13.3(10.8-16.3)$ & $19.9(16.4-24.1)$ & & \\
\hline Moderate & $2.2(1.7-2.9)$ & $1.0(0.3-3.5)$ & $0.6(0.3-1.6)$ & $2.8(1.7-4.6)$ & $2.6(1.7-3.8)$ & $4.4(3.1-6.3)$ & $7.3(5.6-9.4)$ & & \\
\hline Severe & $0.5(0.4-0.8)$ & $0.5(0.2-1.4)$ & 0 & $0.3(0.1-0.9)$ & $0.3(0.1-0.8)$ & $0.8(0.4-1.7)$ & $2.3(1.5-3.5)$ & & \\
\hline
\end{tabular}

DVA = distance visual acuity; NVA: near visual acuity. NOTE = Subjective visual assessment results were related to problems: none, mild problems, moderate problems, severe problems. Weighted proportion and 95\% Confident intervals are shown; $p$ (age) refers to statistical differences in the three age groups; $p$ (sex) refers to differences in gender, with of the age group; subjective visual acuity is assessed as vision problems mentioned by the patient.

outcomes, the co-occurrence of various chronic conditions could be related to a higher risk of visual impairment [52]. People with several chronic conditions, such as cardiovascular conditions, diabetes or arthritis, may have cumulative risk due to vascular, neurodegenerative, biochemical or inflammatory pathways. Some of these relationships have been studied independently in some conditions. For example, diabetes is related to cataracts and diabetic retinopathy, and arthritis has been associated with a higher risk of cataracts [20,53,54]. However, it is known that not only diabetes but also hypertension and hypercholesterolemia are risk factors for diabetic retinopathy so, in this case, cumulative effects are possible $[55,56]$.

Stroke was associated with a high odds of distance and near visual impairment (OR: 1.59 [CI 1.05-2.42]; OR: 3.01 [CI 1.86-4.87]). It is known that stroke is related to a range of visual sequelae, such as low vision, hemianopia, quadrantanopia and motility disorders, but little information is available at an epidemiological level [57]. Low vision may be due to vascular pathology or other ocular abnormalities [58]. Rowe et al. found that up to $92 \%$ of stroke survivors have some form of visual impairment [57]. Our results support this relationship and highlight the need for visual assessment after stroke. We also found a higher odds of distance visual impairment in respondents with arthritis. The relationship between arthritis and vision loss is poorly understood and may also be multifactorial. Firstly, extra-articular arthritis symptoms may include uveitis, ulcerative keratitis, scleritis, severe Sjögren syndrome and other conditions directly associated with vision loss $[59,60]$. Moreover, medication for arthritis such as corticoids or chloroquine/hydroxicloroquine have been associated with an increased prevalence of glaucoma, cataracts or retinopathy [61-64]. There is, however, no clear evidence on the relationship between osteoarthrosis and visual impairment. At an epidemiological level, there are few data on this issue but it has recently been suggested that there is a higher risk of eye diseases in patients with joint diseases [65]. Finally, individual odds of distance 
Table 4 Association between chronic physical conditions and poor visual acuity

\begin{tabular}{ccccc}
\hline & DVA (OR) & DVA (AOR) & NVA (OR) & NVA (AOR) \\
\hline Angina & $1.57(1.17-2.11)$ & $1.12(0.84-1.51)$ & $1.43(1.07-1.91)$ & $1.07(0.78-1.48)$ \\
Asthma & $1.42(1.04-1.95)$ & $1.02(0.72-1.44)$ & $1.38(0.99-1.93)$ & $1.04(0.70-1.54)$ \\
Hypertension & $1.28(1.08-1.52)$ & $0.87(0.73-1.04)$ & $1.51(1.23-1.78)$ & $1.10(0.94-1.28)$ \\
Edentulism & $1.70(1.33-2.18)$ & $1.12(0.89-1.43)$ & $1.74(1.42-2.14)$ & $1.16(0.96-1.41)$ \\
$\quad \begin{array}{l}\text { Diabetes } \\
\text { Arthritis }\end{array}$ & $1.59(1.28-1.98)$ & $1.27(1.01-1.60)$ & $1.22(0.86-1.75)$ & $1.15(0.86-1.52)$ \\
Chronic Lung D & $2.30(1.92-2.75)$ & $1.79(1.46-2.21)$ & $1.63(1.33-1.98)$ & $1.16(0.97-1.40)$ \\
$\quad$ Stroke & $1.38(0.99-1.93)$ & $1.02(0.74-1.42)$ & $1.34(0.90-2.02)$ & $1.06(0.70-1.60)$ \\
Number of physical conditions & $3.53(2.18-5.73)$ & $3.01(1.86-4.87)$ \\
$\quad 1$ & $1.87(1.24-2.83)$ & $1.59(1.05-2.42)$ & & $1.33(1.13-1.57)$ \\
$\quad$ & $1.67(1.35-2.08)$ & & $1.63(1.38-1.94)$ & $1.43(1.13-1.81)$ \\
$\quad \mathbf{2}$ & $1.95(1.51-2.51)$ & $1.32(1.07-1.63)$ & $2.06(1.64-2.60)$ & $1.69(1.27-2.24)$ \\
\hline
\end{tabular}

DVA = distance visual acuity; NVA: near visual acuity; OR= Odds Ratio; $A O R=$ Adjusted Odds Ratio.

Note $=$ Results with 95\% Confidence interval. In bold, statistically significant $(p<0.05)$. AORs are based on logistic regression model including all medical conditions, age, gender, educational level, marital status, and urbanicity. For number of physical conditions, the adjusted models included number of physical conditions, age, gender, educational level, marital status, and urbanicity.

visual impairment was increased in diabetic patients, as expected. However, this association was slight and was not found in the case of near visual acuity, distance subjective visual acuity and near subjective visual acuity. We hypothesize that adjusting by the time from the onset of diabetes could impact the results with diabetes but this information was not available in our study.

With regard to mental health, our results show a clear association between visual impairment and depression. Although visual impairment and depression have been associated in working age adults [66], there is controversy on this topic in older adults $[2,22,24,25,67,68]$. Variability in the studies arises with regard to the type of visual assessment used, including objective visual acuity, medical-record review, presence of age-related eye-disease or vision-loss severity with functional screening. Besides objective measures, the need for measures that accurately assess the degree of visual impairment experienced by the person has been highlighted $[69,70]$. Self-experienced visual loss may be important as this could lead to disability, functional decline, and communicative and social isolation [66,71-74]. In our case, we tested both objective and subjective visual acuity to analyze the nature of their relationships with depression and other mental conditions. We found a stronger association between depression and subjective visual impairment, which highlights the importance of the self-perceived impairment. In fact, the Health Care Policy and Research Cataract Surgery Guidelines suggest that one important indication for cataract surgery may be the degree of functional disability rather than objective visual assessment alone [75,76]. The differing results in objective and subjective visual impairment with regard to depression could be influenced by the negative perception that these patients may have about themselves. Anxiety showed no association with visual acuity, corroborating previous studies in adults and the elderly [21,23,24,77-79]. There is, however, some controversy as higher rates of anxiety have been observed in populations with some ocular conditions $[2,80]$. Our study adds valuable information regarding anxiety because there are relatively few studies on this subject and in most cases they did not have a clear definition of anxiety. Other less-specific variables were used, such as concern about blindness. Moreover, our study deals with objective and subjective visual impairment, providing a general evaluation of the impact of visual performance on anxiety. The relevance of our results is reinforced by the fact that we have used the CIDI questionnaire, a comprehensive, standardized interview that

Table 5 Association between poor visual acuity and variables related to mental health and cognitive functioning

\begin{tabular}{lcccccc}
\hline & Depression (OR) & Depression (AOR) & Anxiety (OR) & Anxiety (AOR) & Cognition (OR) & Cognition (AOR) \\
\hline Distance VA & $1.64(1.27-2.12)$ & $1.25(0.97-1.61)$ & $0.90(0.47-1.71)$ & $0.74(0.39-1.40)$ & $1.47(1.17-1.86)$ & $1.27(1.02-1.59)$ \\
Near VA & $1.39(1.01-1.93)$ & $1.10(0.78-1.53)$ & $0.97(0.55-1.73)$ & $0.83(0.43-1.64)$ & $1.72(1.46-2.02)$ & $1.51(1.28-1.85)$ \\
Subjective distance VA & $2.80(2.10-3.74)$ & $1.61(1.14-2.27)$ & $2.15(1.14-4.04)$ & $1.47(0.71-3.04)$ & $2.05(1.44-2.90)$ & $1.43(1.00-2.06)$ \\
Subjective near VA & $2.40(1.74-3.30)$ & $1.48(1.03-2.13)$ & $0.42(0.09-1.93)$ & $0.27(0.05-1.36)$ & $2.96(1.92-4.55)$ & $2.40(1.52-3.71)$ \\
\hline
\end{tabular}

VA = visual acuity; OR = Odds Ratio; $A O R=$ Adjusted Odds Ratio.

Note $=$ Adjusted models included age, gender, education level, marital status, urbanicity and all chronic physical conditions. Results with $95 \%$ Confidence interval. In bold, statistically significant $(p<0.05)$. 
has demonstrated particular usefulness in epidemiological and cross-cultural studies [81]. By using the CIDI, our results can be compared with those of other studies using the same approach.

Finally, cognitive functioning was found to be associated with distance and near visual impairment, at both objective and subjective levels. The strongest relationship was observed in subjective near visual impairment. Mixed results have previously been found with regard to visual performance and cognitive functioning in the elderly population [29-33,82].

Simulated visual impairment has shown cognitive slowing in adults, especially in the elderly [83,84]. Moreover, other studies have found a clear relationship between visual performance and cognitive disorders such as Alzheimer's and Parkinson's disease [85-87]. The interaction between vision and cognition is not fully understood. On the one hand, visual loss could lead to deprivation of sensory input, leading to cerebral structural or functional changes. On the other hand, a common physiological pathway could be involved. A loss of retinal ganglion cells and impairment of the ventral and dorsal pathways in patients with Alzheimer's disease has been described $[85,88]$. Besides the etiopathogenic implications of the association between vision and cognition, this interaction should be highlighted because coexisting visual and cognitive impairment has been related to a higher risk of disability [89].

Our study has several limitations. Cross-sectional studies identify associations but do not allow cause and effect relationships to be determined. Moreover, age effects may not be distinguished from cohort effects. Longitudinal studies are needed to confirm these results. Multimorbidity research would benefit from standardized inclusion and definition of diseases [65]. In some cases, the Expanded Diagnosis Clusters adapted of the $\mathrm{ACG}^{\circ}$ system have been used, an exhaustive method that is complex to apply outside the clinical setting and where poor integration of health care levels exists [17]. It is known that a higher number of conditions results in a higher proportion of multimorbidity [19]. For our study, the choice of chronic conditions was made according to the SAGE study, focusing on a limited number of conditions that are highly prevalent in the general population and constitute major causes of disability. This methodology allows the work to be conducted across countries. Self-reported data could affect the results, although this would be minimal as acceptable correlation between self-reported and medical-record diagnosis has been found [90,91]. With respect to vision itself, future studies should include binocular visual acuity assessment and other visual tests such as contrast sensitivity and glare disability. Another limitation is the fact that some differences could arise when using distinct subjective strategies in the visual assessment, which could affect the results [92]. Moreover, since visual impairment becomes more frequent in advanced ages, participants in their fifties could potentially skew the results of the analyses. Consequently, we performed a sensitivity analysis with participants over 65 years which showed similar results compared with the results of the global sample (50 years and over). Finally, poorer results in cognitive functioning may appear in patients with vision loss when the tests include vision tasks $[93,94]$. In our study, only the verbal memory tests included a reading part. However, the interviewer read the words aloud if the respondent had reading difficulties, so this bias may be minimized.

\section{Conclusion}

The results of our study contribute to a deeper understanding of visual impairment and its relationship with chronic physical conditions and mental disorders. There seems to be a clear association between a higher number of co-occurring chronic physical conditions and poorer results in distance and near visual functioning. Elderly patients with multimorbidity would benefit from extra eye-care and this would also improve the efficiency of the health care system. At an independent level, suffering from stroke and arthritis is highly associated with poorer results in visual functioning. The presence of these conditions could be triggers for visual impairment. With regard to mental health, poor subjective but not objective visual functioning is closely related to depression, highlighting the importance of subjective perception in depression. Since poor cognition has also been related to poor visual functioning, it would be advisable to monitor mood and cognitive functioning in people suffering from visual disorders.

\section{Competing interests}

None of the authors have any proprietary interests or conflicts of interest related to this submission.

This submission has not been published anywhere previously and it is not simultaneously being considered by any other publication.

\section{Authors' contributions}

NG: Participated in the database management, drafted the paper, carried out the statistical analyses and worked on the interpretation of data. He also gave final approval of the version to be published and agreed to be accountable for all aspects of the work in ensuring that questions related to the accuracy or integrity of any part of the work are appropriately investigated and resolved. BO: Participated in the acquisition of data, database management, critical revision of the paper, and carried out the statistical analyses. She also gave final approval of the version to be published and agreed to be accountable for all aspects of the work in ensuring that questions related to the accuracy or integrity of any part of the work are appropriately investigated and resolved. EL: Participated in the database management and critical revision of the paper. She also gave final approval of the version to be published and agreed to be accountable for all aspects of the work in ensuring that questions related to the accuracy or integrity of any part of the work are appropriately investigated and resolved. MVM: Participated in the study design, database management, statistical support and critical revision of the paper. She also gave final approval of the version to be published and agreed to be accountable for all aspects of the 
work in ensuring that questions related to the accuracy or integrity of any part of the work are appropriately investigated and resolved. MM: Participated in the acquisition of data, database management and critical revision of the paper. She also gave final approval of the version to be published and agreed to be accountable for all aspects of the work in ensuring that questions related to the accuracy or integrity of any part of the work are appropriately investigated and resolved. JLA: Participated in the study design, acquisition of data, interpretation of data and critical revision of the paper. He also gave final approval of the version to be published and agreed to be accountable for all aspects of the work in ensuring that questions related to the accuracy or integrity of any part of the work are appropriately investigated and resolved. JMH: Participated in the study design, acquisition of data, interpretation of data and critical revision of the paper. He also gave final approval of the version to be published and agreed to be accountable for all aspects of the work in ensuring that questions related to the accuracy or integrity of any part of the work are appropriately investigated and resolved.

\section{Acknowledgements}

The research leading to these results received funding from the European Community's Seventh Framework Programme (FP7/2007-2013) under grant agreement number 223071 (COURAGE in Europe) and the Spanish Ministry of Education, Culture and Sport (FPU12/05661). Additional support was provided by funds from the Instituto de Salud Carlos III-FIS, research grants numbers PS09/00295 and PS09/01845, from the Spanish Ministry of Science and Innovation's ACI-Promociona (ACI2009-1010). The study was supported by the Centro de Investigación Biomédica en Red de Salud Mental (CIBERSAM), Instituto de Salud Carlos III. This article is part of a PhD programme developed in the Public Health Department of the Universitat de Barcelona, Spain.

\section{Author details}

'Parc Sanitari Sant Joan de Déu, Universitat de Barcelona, Dr Antoni Pujades, 42, 08830 Barcelona, Sant Boi de Llobregat, Spain. ${ }^{2}$ Fundació Sant Joan de Déu, Santa Rosa, 39-57, 08950 Barcelona, Esplugues de Llobregat, Spain. ${ }^{3}$ Instituto de Salud Carlos III, Centro de Investigación Biomédica en Red de Salud Mental, CIBERSAM, Monforte de Lemos 3-5. Pabellón 1128029 Madrid, Spain. ${ }^{4}$ Department of Psychiatry, Universidad Autónoma de Madrid, Arzobispo Morcillo s/n 28029, Madrid, Spain. Instituto de Investigación Sanitaria Princesa (IP), Diego de León, 62, 28006 Madrid, Spain.

Received: 2 April 2014 Accepted: 26 June 2014

Published: 8 August 2014

\section{References}

1. Lee DJ, Gómez-Marín O, Lam BL, Zheng DD, Caban A: Visual impairment and morbidity in community-residing adults: the national health interview survey 1986-1996. Ophthalmic Epidemiol 2005, 12(1):13-17.

2. Li Y, Crews JE, Elam-Evans LD, Fan AZ, Zhang X, Elliott AF, Balluz L: Visual impairment and health-related quality of life among elderly adults with age-related eye diseases. Qual Life Res 2011, 20(6):845-852.

3. Finger RP, Fenwick E, Marella M, Dirani M, Holz FG, Chiang PP-C, Lamoureux EL: The impact of vision impairment on vision-specific quality of life in Germany. Invest Ophthalmol Vis Sci 2011, 52(6):3613-3619.

4. Chia E-M, Mitchell P, Rochtchina E, Foran S, Wang JJ: Unilateral visual impairment and health related quality of life: the Blue Mountains Eye Study. Br J Ophthalmol 2003, 87(4):392-395.

5. Du Toit R, Palagyi A, Ramke J, Brian G, Lamoureux EL: The impact of reduced distance and near vision on the quality of life of adults in Timor-Leste. Ophthalmology 2010, 117(12):2308-2314.

6. Lopez D, McCaul KA, Hankey GJ, Norman PE, Almeida OP, Dobson AJ, Byles $J E$, Yeap BB, Flicker L: Falls, injuries from falls, health related quality of life and mortality in older adults with vision and hearing impairment-is there a gender difference? Maturitas 2011, 69(4):359-364.

7. Grue EV, Ranhoff AH, Noro A, Finne-Soveri H, Jensdóttir AB, Ljunggren $G$, Bucht $G$, Björnson $L$, Jonsén $E$, Schroll $M$, Jónsson $P V$ : Vision and hearing impairments and their associations with falling and loss of instrumental activities in daily living in acute hospitalized older persons in five Nordic hospitals. Scand J Caring Sci 2009, 23(4):635-643.

8. Zheng DD, Christ SL, Lam BL, Arheart KL, Galor A, Lee DJ: Increased mortality risk among the visually impaired: the roles of mental well- being and preventive care practices. Invest Ophthalmol Vis Sci 2012, 53(6):2685-2692

9. World Health Organization: Global Initiative for the Elimination of Avoidable Blindness. Action Plan 2006-2011. France: WHO Library Cataloguing-in-Publication Data; 2007:90. [http://www.who.int/blindness/Vision2020_report.pdf]

10. World Health Organization: International Classification of Functioning, Disability and Health: ICF. Geneva: WHO Library Cataloguing-in-Publication Data; 2001:299.

11. Finger RP, Bertram B, Wolfram C, Holz FG: Blindness and visual impairment in Germany: a slight fall in prevalence. Dtsch Arztebl Int 2012, 109(27-28):484-489.

12. Sainz-Gómez $C$, Fernández-Robredo $P$, Salinas-Alamán $A$, Montañés JM, Escudero Berasategui JM, Guillén-Grima F, Ruiz-Moreno JM, García-Layana A: Prevalence and causes of bilateral blindness and visual impairment among institutionalized elderly people in Pamplona, Spain. Eur J Ophthalmol 2010, 20(2):442-450.

13. World Health Organization: Executive board: draft action plan for the prevention of avoidable blindness and visual impairment 2014-2019. Universal eye health: a global action plan 2014-2019. 2013. http://apps. who.int/gb/ebwha/pdf_files/EB132/B132_9-en.pdf.

14. Lee DJ, Lam BL, Gómez-Marín O, Zheng DD, Caban AJ: Concurrent hearing and visual impairment and morbidity in community-residing adults: the National Health Interview Survey, 1986 to 1996. J Aging Health 2005, 17(5):531-546.

15. United Nations. Department of Economic and Social Affairs. Population Division: Population ageing and development 2012. 2012. http://www.un. org/esa/population/publications/2012WorldPopAgeingDev_Chart/ 2012PopAgeingandDev_WallChart.pdf.

16. Olusanya B, Onoja G, Ibraheem W, Bekibele C: Profile of patients presenting at a low vision clinic in a developing country. BMC Ophthalmol 2012, 12:31. doi:10.1186/1471-2415-12-31.

17. Prados-Torres A, Poblador-Plou B, Calderón-Larrañaga A, Gimeno-Feliu LA, González-Rubio F, Poncel-Falcó A, Sicras-Mainar A, Alcalá-Nalvaiz JT: Multimorbidity patterns in primary care: interactions among chronic diseases using factor analysis. PLoS One 2012, 7(2):e32190. doi:10.1371/journal. pone.0032190.

18. Uijen AA, van de Lisdonk EH: Multimorbidity in primary care: prevalence and trend over the last 20 years. Eur J Gen Pract 2008, 14(Suppl 1):28-32.

19. Marengoni A, Angleman S, Melis R, Mangialasche F, Karp A, Garmen A, Meinow B, Fratiglioni L: Aging with multimorbidity: a systematic review of the literature. Ageing Res Rev 2011, 10(4):430-439.

20. Tarr JM, Kaul K, Wolanska K, Kohner EM, Chibber R: Retinopathy in diabetes. Adv Exp Med Biol 2012, 771:88-106.

21. Lotery A, Xu X, Zlatava G, Loftus J: Burden of illness, visual impairment and health resource utilisation of patients with neovascular age-related macular degeneration: results from the UK cohort of a five-country cross-sectional study. Br J Ophthalmol 2007, 91(10):1303-1307.

22. Hayman KJ, Kerse NM, La Grow SJ, Wouldes T, Robertson MC, Campbell AJ: Depression in older people: visual impairment and subjective ratings of health. Optom Vis Sci 2007, 84(11):1024-1030.

23. Donoyama N, Takeda F: Mental health and related factors among massage practitioners with visual impairment. Ind Health 2007, 45(2):191-198.

24. Evans JR, Fletcher AE, Wormald RPL: Depression and anxiety in visually impaired older people. Ophthalmology 2007, 114(2):283-288.

25. Lamoureux EL, Fenwick E, Moore K, Klaic M, Borschmann K, Hill K: Impact of the severity of distance and near-vision impairment on depression and vision-specific quality of life in older people living in residential care. Invest Ophthalmol Vis Sci 2009, 50(9):4103-4109.

26. Lam BL, Christ SL, Lee DJ, Zheng DD, Arheart KL: Reported visual impairment and risk of suicide: the 1986-1996 national health interview surveys. Arch Ophthalmol 2008, 126(7):975-980.

27. Chang LYL, Lowe J, Ardiles A, Lim J, Grey AC, Robertson K, Danesh-Meyer H, Palacios AG, Acosta ML: Alzheimer's disease in the human eye. Clinical tests that identify ocular and visual information processing deficit as biomarkers. Alzheimers Dement 2014, 10(2):251-261.

28. Elyashiv SM, Shabtai EL, Belkin M: Correlation between visual acuity and cognitive functions. Br J Ophthalmol 2014, 98(1):129-132.

29. Sloan FA, Ostermann J, Brown DS, Lee PP: Effects of changes in selfreported vision on cognitive, affective, and functional status and living arrangements among the elderly. Am J Ophthalmol 2005, 140(4):618-627. 
30. Elliott AF, McGwin G, Owsley C: Vision impairment among older adults residing in assisted living. J Aging Health 2013, 25(2):364-378.

31. Ong SY, Cheung CY, Li X, Lamoureux EL, Ikram MK, Ding J, Cheng CY, Haaland BA, Saw SM, Venketasubramanian N, Chen CP, Wong TY: Visual impairment, age-related eye diseases, and cognitive function: the Singapore Malay Eye study. Arch Ophthalmol 2012, 130(7):895-900

32. Prince $M$, Acosta D, Ferri CP, Guerra M, Huang Y, Jacob KS, Jotheeswaran AT, Liu Z, Rodriguez JJ, Salas A, Sosa AL, Williams JD: The association between common physical impairments and dementia in low and middle income countries, and, among people with dementia, their association with cognitive function and disability. A 10/66 Dementia Research Group population-based study. Int J Geriatr Psychiatry 2011, 26(5):511-519.

33. Clemons TE, Rankin MW, McBee WL: Cognitive impairment in the Age-related Eye disease study: AREDS report no. 16. Arch Ophthalmol 2006, 124(4):537-543.

34. Leonardi M, Chatterji S, Koskinen S, Ayuso-Mateos JL, Haro JM, Frisoni G, Frattura L, Martinuzzi A, Tobiasz-Adamczyk B, Gmurek M, Serrano R, Finocchiaro C, on behalf of COURAGE in Europe Project's Consortium: Determinants of health and disability in ageing population: the COURAGE in Europe project (Collaborative Research on Ageing in Europe). Clin Psychol Psychother 2013. doi:10.1002/cpp.1856.

35. World Health Organization: WHO | Process of Translation and Adaptation of Instruments. World Health Organization. Available from: http://www.who.int/ substance_abuse/research_tools/translation/en/.

36. Ustun TB, Chatterji S, Mechbal A, Murray CJL, WHS collaborating groups: Chapter X: Quality Assurance in Surveys: Standards, Guidelines and Procedures. In Household Sample Surveys in Developing and Transition Countries. Edited by United Nations. New York: United Nations Publications; 2005:199-230. [http://unstats.un.org/unsd/hhsurveys/pdf/ Household_surveys.pdf]

37. Hinton R, Moody RL, Davis AW, Thomas SF: Osteoarthritis: diagnosis and therapeutic considerations. Am Fam Physician 2002, 65(5):841-848.

38. Global initiative for Chronic Obstructive Lung Disease: Global strategy for the diagnosis, management, and prevention of chronic obstructive pulmonary disease. 2013. http://www.goldcopd.org/uploads/users/files/ GOLD_Report_2013_Feb20.pdf.

39. Global Initiative for Asthma: Global strategy for asthma management and prevention. 2012. http://www.ginasthma.org/local/uploads/files/ GINA_Report_2014_Aug12.pdf.

40. National Collaboratoring Centre for Chronic Conditions: NICE Clinical Guideline 68: Stroke, Diagnosis and Initial Management of Acute Stroke and Transient Ischaemic Attack (TIA). NHS NICE; 2008. http://www.nice.org.uk/ guidance/cg68/resources/guidance-stroke-pdf.

41. American Optometric Association: Optometric clinical practice guideline: care of the adult patient with cataract. 2004. http://www.aoa.org/ documents/CPG-8.pdf.

42. Alves $L$, Cesar JA, Horta BL: Prevalence of angina pectoris in Pelotas, South of Brazil. Arq Bras Cardiol 2010, 95(2):179-185.

43. Kowal P, Chatterii S, Naidoo N, Biritwum R, Fan W, Lopez Ridaura R, Maximova T, Arokiasamy P, Phaswana-Mafuya N, Williams S, Snodgrass JJ, Minicuci N, D'Este C, Peltzer K, Boerma JT, SAGE Collaborators: Data resource profile: the World Health Organization Study on global AGEing and adult health (SAGE). Int J Epidemiol 2012, 41(6):1639-1649.

44. American Psychiatric Association: Diagnostic and Statistical Manual of Mental Disorders (DSM-IV). Washington, DC: American Psychiatric Association; 1994

45. Morris JC, Heyman A, Mohs RC, Hughes JP, van Belle G, Fillenbaum G, Mellits ED, Clark C: The Consortium to Establish a Registry for Alzheimer's Disease (CERAD). Part I. Clinical and neuropsychological assessment of Alzheimer's disease. Neurology 1989, 39(9):1159-1165.

46. Psychological Corporation: The WAIS III - WMS III updated technical manual. San Antonio, TX: Psychological Corporation; 2002.

47. Perales J, Martin S, Ayuso-Mateos JL, Chatterji S, Garin N, Koskinen S, Leonardi M, Miret M, Moneta V, Olaya B, Tobiasz-Adamczyk B, Haro JM: Factors associated with active aging in Finland, Poland, and Spain. Int Psychogeriatr 2014, 1-13. http://dx.doi.org/10.1017/S1041610214000520.

48. He W, Muenchrath M, Kowal P: A cross-country study of health and wellbeing of the older populations in SAGE countries, 2007-2010. 2012 Available from: [http://www.census.gov/prod/2012pubs/p95-12-01.pdf]

49. Keeffe JE, Lovie-Kitchin JE, Maclean H, Taylor HR: A simplified screening test for identifying people with low vision in developing countries. Bull World Health Organ 1996, 74(5):525-532.
50. Landis JR, Koch GG: The measurement of observer agreement for categorical data. Biometrics 1977, 33(1):159-174.

51. Rahi JS, Cumberland PM, Peckham CS: Visual impairment and visionrelated quality of life in working-age adults: findings in the 1958 British birth cohort. Ophthalmology 2009, 116(2):270-274.

52. Searle SD, Mitnitski A, Gahbauer EA, Gill TM, Rockwood K: A standard procedure for creating a frailty index. BMC Geriat 2008. doi:10.1186/14712318-8-24.

53. Richter GM, Torres M, Choudhury F, Azen SP, Varma R: Risk factors for cortical, nuclear, posterior subcapsular, and mixed lens opacities: the Los Angeles Latino Eye Study. Ophthalmology 2012, 119(3):547-554.

54. Falsarella GR, Coimbra IB, Barcelos CC, Costallat LT, Carvalho OM, Coimbra AM: Prevalence and factors associated with rheumatic diseases and chronic joint symptoms in the elderly. Geriatr Gerontol Int 2013, 13(4):1043-1050.

55. Stitt AW, Lois N, Medina RJ, Adamson P, Curtis TM: Advances in our understanding of diabetic retinopathy. Clin Sci (Lond) 2013, 125(1):1-17.

56. Sen K, Misra A, Kumar A, Pandey RM: Simvastatin retards progression of retinopathy in diabetic patients with hypercholesterolemia. Diabetes Res Clin Pract 2002, 56(1):1-11.

57. Rowe F, Brand D, Jackson CA, Price A, Walker L, Harrison S, Eccleston C, Scott C, Akerman N, Dodridge C, Howard C, Shipman T, Sperring U, MacDiarmid S, Freeman C: Visual impairment following stroke: do stroke patients require vision assessment? Age Ageing 2009, 38(2):188-193.

58. Lotery A: Correctable visual impairment in stroke rehabilitation patients. Age Ageing 2000, 29(3):221-222.

59. Cojocaru M, Cojocaru IM, Silosi I, Vrabie CD, Tanasescu R: Extra-articular manifestations in rheumatoid arthritis. Maedica 2010, 5(4):286-291.

60. Ozdal PC, Vianna RNG, Deschênes J: Visual outcome of juvenile rheumatoid arthritis-associated uveitis in adults. Ocul Immunol Inflamm 2005, 13(1):33-38.

61. Marmor MF, Kellner U, Lai TYY, Lyons JS, Mieler WF: Revised recommendations on screening for chloroquine and hydroxychloroquine retinopathy. Ophthalmology 2011, 118(2):415-422.

62. Razeghinejad MR, Katz LJ: Steroid-induced iatrogenic glaucoma. Ophthalmic Res 2012, 47(2):66-80.

63. James ER: The etiology of steroid cataract. J Ocul Pharmacol Ther 2007 23(5):403-420

64. Shah SP, Desai CK, Desai MK, Dikshit RK: Steroid-induced central serous retinopathy. Indian J Pharmacol 2011, 43(5):607-608.

65. Kirchberger I, Meisinger C, Heier M, Zimmermann A-K, Thorand B, Autenrieth CS, Peters A, Ladwig KH, Döring A: Patterns of multimorbidity in the aged population. Results from the KORA-Age study. PLoS One 2012 7(1):e30556.

66. Nyman SR, Gosney MA, Victor CR: Psychosocial impact of visual impairment in working-age adults. Br J Ophthalmo/ 2010, 94(11):1427-1431.

67. Brody BL, Gamst AC, Williams RA, Smith AR, Lau PW, Dolnak D, Rapaport $\mathrm{MH}$, Kaplan RM, Brown SI: Depression, visual acuity, comorbidity, and disability associated with age-related macular degeneration. Ophthalmology 2001, 108(10):1893-1900. discussion 1900-1.

68. Horowitz A, Reinhardt JP, Kennedy GJ: Major and subthreshold depression among older adults seeking vision rehabilitation services. Am J Geriatr Psychiatry 2005, 13(3):180-187.

69. Margolis MK, Coyne K, Kennedy-Martin T, Baker T, Schein O, Revicki DA Vision-specific instruments for the assessment of health-related quality of life and visual functioning: a literature review. Pharmacoeconomics 2002, 20(12):791-812

70. Massof RW, Rubin GS: Visual function assessment questionnaires. Surv Ophthalmol 2001, 45(6):531-548.

71. Alma MA, van der Mei SF, Melis-Dankers BJM, van Tilburg TG, Groothoff JW, Suurmeijer TPBM: Participation of the elderly after vision loss. Disabil Rehabil 2011, 33(1):63-72.

72. Heine $\mathrm{C}$, Browning $\mathrm{CJ}$ : Communication and psychosocial consequences of sensory loss in older adults: overview and rehabilitation directions. Disabil Rehabil 2002, 24(15):763-773.

73. Steinman BA, Allen SM: Self-reported vision impairment and its contribution to disability among older adults. J Aging Health 2012 24(2):307-322.

74. Jampel HD, Frick KD, Janz NK, Wren PA, Musch DC, Rimal R, Lichter PR, CIGTS Study Group: Depression and mood indicators in newly diagnosed glaucoma patients. Am J Ophthalmol 2007, 144(2):238-244. 
75. Lee PP, Whitcup SM, Hays RD, Spritzer K, Javitt J: The relationship between visual acuity and functioning and well-being among diabetics. Qual Life Res 1995, 4(4):319-323.

76. The Royal College of Ophthalmologists: Cataract Surgery Guidelines. 2010

77. Cumurcu T, Cumurcu BE, Celikel FC, Etikan I: Depression and anxiety in patients with pseudoexfoliative glaucoma. Gen Hosp Psychiatry 2006, 28(6):509-515.

78. Jangra D, Ganesh A, Thackray R, Austin L, Ulster A, Sutherland J, Levin AV: Psychosocial adjustment to visual loss in patients with retinitis pigmentosa. Ophthalmic Genet 2007, 28(1):25-30.

79. Janz NK, Wren PA, Lichter PR, Musch DC, Gillespie BW, Guire KE, Mills RP, CIGTS Study Group: The Collaborative Initial Glaucoma Treatment Study: interim quality of life findings after initial medical or surgical treatment of glaucoma. Ophthalmology 2001, 108(11):1954-1965.

80. Mabuchi F, Yoshimura K, Kashiwagi K, Shioe K, Yamagata Z, Kanba S, lijima $H$, Tsukahara S: High prevalence of anxiety and depression in patients with primary open-angle glaucoma. J Glaucoma 2008, 17(7):552-557.

81. Haro JM, Arbabzadeh-Bouchez S, Brugha TS, de Girolamo G, Guyer ME, Jin R, Lepine JP, Mazzi F, Reneses B, Vilagut G, Sampson NA, Kessler RC: Concordance of the Composite International Diagnostic Interview Version 3.0 (CIDI 3.0) with standardized clinical assessments in the WHO World Mental Health surveys. Int J Methods Psychiatr Res 2006, 15(4):167-180.

82. Gussekloo J, de Craen AJM, Oduber C, van Boxtel MPJ, Westendorp RGJ: Sensory impairment and cognitive functioning in oldest-old subjects: the Leiden 85+ Study. Am J Geriatr Psychiatry 2005, 13(9):781-786.

83. Wood J, Chaparro A, Anstey K, Lacherez P, Chidgey A, Eisemann J, Gaynor A, La P: Simulated visual impairment leads to cognitive slowing in older adults. Optom Vis Sci 2010, 87(12):1037-1043.

84. Wood JM, Chaparro A, Anstey KJ, Hsing YE, Johnsson AK, Morse AL, Wainwright SE: Impact of simulated visual impairment on the cognitive test performance of young adults. Br J Psychol 2009, 100(Pt 3):593-602.

85. Kirby E, Bandelow S, Hogervorst E: Visual impairment in Alzheimer's disease: a critical review. J Alzheimers Dis 2010, 21(1):15-34.

86. UC EY, Rizzo M, Anderson SW, Qian S, Rodnitzky RL, Dawson JD: Visual dysfunction in Parkinson disease without dementia. Neurology 2005 65(12):1907-1913.

87. Archibald NK, Clarke MP, Mosimann UP, Burn DJ: Visual symptoms in Parkinson's disease and Parkinson's disease dementia. Mov Disord 2011, 26(13):2387-2395.

88. Iseri PK, Altinaş O, Tokay T, Yüksel N: Relationship between cognitive impairment and retinal morphological and visual functional abnormalities in Alzheimer disease. J Neuroophthalmol 2006, 26(1):18-24.

89. Whitson HE, Cousins SW, Burchett BM, Hybels CF, Pieper CF, Cohen HJ: The combined effect of visual impairment and cognitive impairment on disability in older people. J Am Geriatr Soc 2007, 55(6):885-891.

90. Kriegsman DM, Penninx BW, van Eijk JT, Boeke AJ, Deeg DJ: Self-reports and general practitioner information on the presence of chronic diseases in community dwelling elderly. A study on the accuracy of patients' self-reports and on determinants of inaccuracy. $J$ Clin Epidemiol 1996, 49(12):1407-1417.

91. Violán C, Foguet-Boreu Q, Hermosilla-Pérez E, Valderas JM, Bolíbar B, Fàbregas-Escurriola M, Brugulat-Guiteras P, Muñoz-Pérez MÁ: Comparison of the information provided by electronic health records data and a population health survey to estimate prevalence of selected health conditions and multimorbidity. BMC Public Health 2013, 13:251. doi:10.1186/1471-2458-13-251.

92. Papas EB, Schultz BL: Repeatability and comparison of visual analogue and numerical rating scales in the assessment of visual quality. Ophthalmic Physiol Opt 1997, 17(6):492-498.

93. Jefferis JM, Collerton J, Taylor J-P, Jagger C, Kingston A, Davies K, Kirkwood T, Clarke MP: The impact of visual impairment on mini-mental state examination scores in the Newcastle 85+ study. Age Ageing 2012, 41(4):565-568.

94. Bertone A, Bettinelli L, Faubert J: The impact of blurred vision on cognitive assessment. J Clin Exp Neuropsychol 2007, 29(5):467-476.

\section{doi:10.1186/1471-2458-14-815}

Cite this article as: Garin et al:: Visual impairment and multimorbidity in a representative sample of the Spanish population. BMC Public Health 2014 14:815.

\section{Submit your next manuscript to BioMed Central and take full advantage of:}

- Convenient online submission

- Thorough peer review

- No space constraints or color figure charges

- Immediate publication on acceptance

- Inclusion in PubMed, CAS, Scopus and Google Scholar

- Research which is freely available for redistribution 